\title{
I Plead Guilty
}

$\mathrm{H}$ AVE you ever sat in a meeting room as a speaker tried to cover 63 slides in a 12 minute talk? Or do you remember the speaker standing next to the overhead projector with a pile of transparencies_-ink still wet from their creation earlier that morning? Of course these can be matched by the poster presenters who pop the staples on their most recent proposals and thumb tack the figures in the allotted space. We usually giggle as slides are projected sideways and as session chairpersons try to stop longwinded speakers. Levity is great, but our colleagues and our research efforts deserve more.

As with most oceanographers, I attend scholarly gatherings for a diverse assortment of disciplines. I recently was at a meeting of geologists and was shocked by the high quality of the presentations - no overheads, only slides, dual screens, simple demonstrative graphics, effective use of color, logical organization. As I wandered the hallways, I saw speaker-ready rooms with people practicing talks. I saw grading sheets that allowed judges to determine best-paper awards.

Obviously I have been corrupted by the evil forces in the realm of oceanography. Oceanographers have a tendency to emphasize substance to the exclusion of style. We are suspicious of the speaker or poster presenter whose product is slick. We believe a well-conceived research project with high-quality data doesn't need Madison Avenue to sell it. Unfortunately, a confused delivery and muddled graphics can turn the best ideas and data into a 12-minute waste of time for the audience. In fact, highquality material and a well-conceived presentation are not mutually exclusive.

What should we do? a) We should practice our talks. We should discover the pitfalls of our presentations (e.g., length) while talking to ourselves in empty rooms. b) For oral presentations, we should stop using figures from written documents. Visual aids for projection should be simple enough that the contents can be grasped in a few seconds. c) We should use the rule of thumb: 1 slide $=1$ minute. Even if we can talk through slides faster, the audience can seldom follow. d) We should not limit our graphics to the software capabilities of our PC or Mac. Some figures may require analog devices-drafting pen and ink. e) Presentations by full professors and senior scientists should be suspect. A person having delivered hundreds of talks and thousands of lectures can develop a lackadaisical attitude.

There are many more rules and suggestions, but we know what they are. Many of us teach our students and junior colleagues how to give effective talks. But we promptly forget the rules, as we are swallowed up by other responsibilities, time constraints, and lackadaisical attitudes. It's time for oceanographers to undergo a renaissance in their presentations. We may not want best-paper awards at our meetings, but how about worst-paper awards? That would make us squirm, and rightly reward those presenters with 63 slides, wet ink, and recycled figures.

- Chuck Nittrouer

Letters are welcome regarding articles, the Quarterdeck editorial, or other matters relevant to Oceanography.

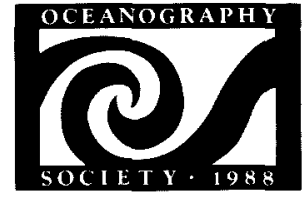

THE OCEANOGRAPHY SOCIETY

1124 Wivenhoe Way Virginia Beach, VA 23454 USA (804) 496-8958; fax: (804) 496-8960 omnet: OCEANOGRAPHY SOCIETY

OFFICERS

Arnold L. Gordon. President Margaret Leinen, President-Elect D. James Baker, Past President Melbourne G. Briscoe, Secretary

David L. Evans, Treasurer

COUNSELORS Richard T. Barber Tommy D. Dickey Richard Jahnke Kevin D. Leaman Constance A. Sancetta W. Stanley Wilson

Charles A. Nittrouer, ex officio

EXECUTIVE DIRECTOR Judi Rhodes

CORPORATE/INSTITUTIONAL SPONSORS Aanderaa Instruments, Inc. Woburn, MA, USA Chishitsu Chosa-Jo, Ibaraki, Japan GE Astro Space Division, Princeton, NJ, USA John G. Shedd Aquarium, Chicago, IL, USA Monterey Bay Aquarium Research Institute, Pacific Grove, CA, USA

National Marine Fisheries Service, Silver Spring, MD, USA

Ober, Kaler, Grimes \& Shriver, Washington, DC, USA

RD Instruments, San Diego, CA, USA

Scripps Institution of Oceanography, La Jolla, CA, USA

Woods Hole Oceanographic Institution, Woods Hole, MA, USA

\section{OCEanography}

EDITOR

Charles A. Nittrouer

Marine Sciences Research Center

State University of New York

Stony Brook, New York 11794 USA

(516) 632-8651; C.NITTROUER

Telefax: (516) 632-8820

EDITORIAL ASSISTANT Michele McTernan

Marine Sciences Research Center

State University of New York

Stony Brook, NY 11794 USA (516) 632-8651

ASSOCIATE EDITORS James W. Ammerman

Department of Oceanography Texas A\&M University College Station, TX 77843 USA

(409) 845-5105; J.AMMERMAN Gregory J. Brunskill

Australian Institute of Marine Science

PMB No. 3, Townsville, M.C.

Queensland 4810, Australia

(77)789211; G.BRUNSKILL Ellen R.M. Druffel

Woods Hole Oceanographic Institution Woods Hole, MA 02543 USA (508) 257-2000; E.DRUFFEL Donald B. Olson RSMAS

University of Miami

Miami, FL 33149 USA

(305) 361-4074; D.OLSON.RSMAS 